\title{
Three-dimensional speckle-tracking echocardiography allows volumetric and strain analysis of the left atrial function in noncompaction cardiomyopathy
}

\author{
Péter Domsik*, Anita Kalapos, Tamás Forster, Attila Nemes \\ Second Department of Medicine and Cardiology Centre, Medical Faculty, University of Szeged, \\ Hungary
}

The goal: Noncompaction cardiomyopathy (NCCM) is a rare cardiomyopathy characterized by a distinctive 2-layered appearance of the myocardium, hypertrabecularization and deep intertrabecular recesses due to arrest of the compaction process of the embryonic endomyocardial morphogenesis. The present study was designed to assess left atrial (LA) volumetric and strain-based functional properties by three-dimensional (3D) speckle-tracking echocardiography (3DSTE) in NCCM.

Patients and Methods: The study comprised 9 consecutive NCCM patients. Due to a low image quality, one patient was excluded from the analysis (mean age: $60.2 \pm 8.2$ years, 3 males). Their results were compared to 20 age- and gendermatched healthy controls (mean age: $50.8 \pm 14.6$ years, 11 males). Complete two-dimensional Doppler echocardiography and 3DSTE were performed in all cases.

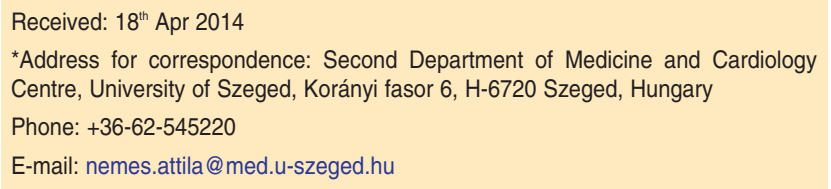

*Address for correspondence: Second Department of Medicine and Cardiology Centre, University of Szeged, Korányi fasor 6, H-6720 Szeged, Hungary Phone: +36-62-545220

E-mail: nemes.attila@med.u-szeged.hu

Results: Calculated LA maximum $(90.3 \pm 19.1 \mathrm{ml}$ vs. 35.8 $\pm 6.3 \mathrm{ml}, \mathrm{p}<0.0001)$ and minimum $(71.3 \pm 19.5 \mathrm{ml}$ vs. 16.3 $\pm 4.7 \mathrm{ml}, \mathrm{p}<0.0001)$ volumes and LA volume before atrial contraction $(81.6 \pm 19.8 \mathrm{ml}$ vs. $24.0 \pm 6.5 \mathrm{ml}, \mathrm{p}<0.0001) \mathrm{sig}-$ nificantly increased in NCCM patients. Total, active and passive LA emptying fractions proved to have decreased in NCCM. Global radial $(8.0 \pm 6.8 \%$ vs, $21.4 \pm 11.5 \%$, p $=0.005)$, circumferential $(9.7 \pm 7.7 \%$ vs. $28.7 \pm 9.7 \%$, p $<0.0001)$, longitudinal $(8.4 \pm 4.1 \%$ vs. $24.5 \pm 6.6 \%$, p $<0.0001), 3 \mathrm{D}(5.7 \pm 5.2 \%$ vs. $13.7 \pm 10.5 \%, p=0.05)$ and area $(17.7 \pm 12.5 \%$ vs. $58.2 \pm 17.3 \%, p<0.0001)$ strains were significantly reduced in NCCM patients as compared to the matched controls.

Conclusions: 3DSTE allows detailed evaluation of LA (dys)function. Increased LA volumes and reduced LA emptying fractions respecting cardiac cycle and reduced LA strain parameters could be demonstrated by DSTE in NCCM.

KEYWORDS: three-dimensional, speckle-tracking, echocardiography, left atrium, noncompaction cardiomyopathy.

CITATION: Cardiol Croat. 2014;9(5-6):187.

\section{Literature}

1. Nemes A, Kalapos A, Domsik P, Forster T. Three-dimensional speckle-tracking echocardiography -- a further step in non-invasive three-dimensional cardiac imaging. Orv Hetil. 2012;153:1570-7. 